\title{
Prevalence of metabolic syndrome in individuals undergoing comprehensive cardiac and general medical check-up at Kathmandu Medical College Teaching Hospital
}

\author{
Karki DB ${ }^{1}$, Neopane A $^{2}$, Joshi $\mathbf{S}^{3}$, Pant $\mathbf{S}^{4}$, Sharma ${ }^{5}$, Shrestha $\mathbf{P}^{6}$, Yogal $\mathbf{R}^{7}$ \\ ${ }^{1}$ Dambar Bahadur Karki, Professor; ${ }^{2}$ Arpana Neopane, Associate Professor; ${ }^{3}$ Surakshya Joshi, Medical Resident; \\ ${ }^{4}$ Subash Pant, Medical Resident; ${ }^{5}$ Lucky Sharma, Medical Resident; ${ }^{7}$ Rijendra Yogal, Medical Officer, Department of \\ Medicine, Kathmandu Medical College Teaching Hospital, Kathmandu, Nepal. \\ ${ }^{4}$ Pradeep Shrestha, Medical Officer, Dhading District Hospital, Dhading, Nepal.
}

\section{Abstract}

Background: Metabolic syndrome represents a constellation of metabolic derangements including insulin resistance, diabetes mellitus, obesity, dyslipidaemia and cardiovascular disease. Since it is associated with higher risk of coronary artery disease and diabetes mellitus, timely detection is important.

Objectives: The main objective of the study was to find out the prevalence of metabolic syndrome in individuals undergoing comprehensive cardiac and general medical check-up at Kathmandu Medical College Teaching Hospital. The other objectives were to find the gender and ethnic prevalence of this condition.

Methods: This is a hospital based cross-sectional study conducted at Kathmandu Medical College Teaching Hospital among 389 healthy participants of both gender and above 20 years of age who underwent comprehensive cardiac and general medical check-up. Metabolic Syndrome was diagnosed using US National Cholesterol Education Program Adult Treatment Panel III.

Results: Out of the 389 subjects, 56 persons were found to be having metabolic syndrome (14.40\%). Metabolic syndrome was more common in female and obese people and the prevalence did not differ with ethnicity. Conclusion: The prevalence of metabolic syndrome in the present study has been found to be $14.40 \%$. It is important to diagnose this condition in time so that subsequent complications can be prevented.

Key Words: Impaired fasting glucose, Metabolic Syndrome, Nepal, Waist circumference.

\section{INTRODUCTION}

$\mathrm{T}^{\mathrm{s}}$ he term Metabolic Syndrome dates back to late 1950s, but it came in common use in late 1970s to describe various associations of risk factors with diabetes that had been noted as early as $1920 s^{1,2}$. In 1977, Haller used the term Metabolic Syndrome for associations of obesity, gout, diabetes mellitus, and hypertension with hyperlipoproteinaemia syndrome ${ }^{3}$. In 1988 in his Banting

Address for correspondence
Dr. DB Karki
Professor and Head
Department of Medicine
Kathmandu Medical College Teaching Hospital,
Kathmandu, Nepal
E-mail: dbkarkikmc@gmail.com

lecture, Gerald M Reaven proposed insulin resistance as the underlying factor and named the constellation of abnormalities Syndrome $\mathrm{X}^{4}$. Hormonal balance of the hypothalamic-pituitary-adrenal axis is upset in this condition. This produces cortisol that results in diabetes mellitus and insulin resistance ${ }^{5}$.

Metabolic Syndrome is becoming an important medical problem of the modern society. The incidence of type 2 diabetes mellitus and coronary artery disease have been found to be high in Metabolic Syndrome by various authors all over the world ${ }^{6-9}$. In a meta-analysis of 16 multi-ethnic cohort studies, the relative risk of developing diabetes ranged from 3.53 to 5.17 depending upon the definition of metabolic syndrome and population studied $^{6}$. Three meta-analysis have found the relative risk of developing cardiovascular disease to be 1.53 to $2.18^{7-9}$. 
There are very few studies about the prevalence of metabolic syndrome from Nepal. A population study from eastern Nepal using NCEP ATP III criteria has revealed $20.7 \%$ prevalence of metabolic syndrome ${ }^{10}$. We conducted this study to find out the prevalence of metabolic syndrome among individuals undergoing comprehensive and general medical check-up.

\section{METHODS}

This is a hospital based cross-sectional study conducted among 389 participants undergoing comprehensive cardiac and general medical check-up at Kathmandu Medical College Teaching Hospital (KMCTH) from December 2009 to September 2012. Comprehensive cardiac and general medical check-up is a general health check-up package at KMCTH offered to healthy participants coming for routine check-up as well as to those attending the medicine out-patient department (OPD) who are willing to undergo a general medical check-up. Criteria for inclusion in the study were: age 20 years or above, both genders, no known co-morbidity other than those under medication for hypertension and diabetes (exception for these two conditions was made because being under medication for diabetes or hypertension is among the criteria for metabolic syndrome). After approval from the Ethical Committee and verbal consent from participants, proforma was filled up and all the details of the anthropometric measurement, physical examination findings and investigations were recorded.

The US National Cholesterol Education Program-Adult Treatment Panel III 2001 (NCEP ATP-III) criteria ${ }^{11}$ were followed in the diagnosis of Metabolic Syndrome. NCEP ATP III criteria required at least three of the following: Waist Circumference $\geq 102 \mathrm{~cm}$ or 40 inch (male), $\geq 88$ $\mathrm{cm}$ or 36 inch (female); triglyceride (TG) $\geq 150 \mathrm{mg} / \mathrm{dl}$ or on treatment; High Density Lipoprotein (HDL) cholesterol $<40 \mathrm{mg} / \mathrm{dL}$ in male and $50 \mathrm{mg} / \mathrm{dL}$ in female, Blood pressure $\geq 130 / 85 \mathrm{~mm} \mathrm{Hg}$ or on treatment; Fasting glucose $\geq 100 \mathrm{mg} / \mathrm{dL}$ or under medication for diabetes. The distribution of demographic (age, sex, ethnicity) and other baseline variables (smoking, alcohol consumption, high total cholesterol [ $\geq 200 \mathrm{mg} / \mathrm{dL}$ ], high waist circumference, high waist:hip ratio $[>0.9$ for females, $>1$ for males] and body mass index (BMI) in those with and without metabolic syndrome was compared. Those patients who were currently smoking or left smoking for less than four weeks prior were considered smokers. Similar criteria were used to define alcohol consumption.

The sample size was calculated based on prevalence data from a population based study from eastern $\mathrm{Nepal}^{10}$. Maintaining a level of significance of $5 \%$, minimum sample size required is 253. Data analysis was done with Statistical Package for Social Sciences (SPSS)-16 and two-sample $t$ test or chi-square test were applied as appropriate. A p-value $<0.05$ was taken as statistically significant.

\section{RESULTS}

Of the total 389 participants, metabolic syndrome was detected in 56 ( 21 males, 35 females), with a prevalence rate of $14.4 \%$ (20.71\% in females and $9.55 \%$ in males).

The distribution of baseline variable is shown in table 1 . Those with metabolic syndrome were of higher age and body mass index (BMI) than those without the syndrome. Similarly female gender, high waist circumference and high waist hip ratio were associated with metabolic syndrome.

Abnormalities of individual component of metabolic syndrome are shown in Table 3. Four out of five participants had impaired fasting glucose or were under medication for diabetes. Obesity and high triglyceride level were also common among the participants. We also tried to evaluate the prevalence of individual components in those with metabolic syndrome (Table 4). 
Table 1: Distribution of Baseline Characteristics among participants with and without metabolic syndrome.

\begin{tabular}{|c|c|c|c|}
\hline Variables & $\begin{array}{c}\text { Metabolic Syndrome } \\
\text { Present }(n=56)\end{array}$ & $\begin{array}{c}\text { Metabolic Syndrome } \\
\text { absent }(n=333)\end{array}$ & $p$ value \\
\hline Age (years), Mean \pm SD & $51.41 \pm 10.19$ & $43.55 \pm 14.53$ & $<0.001$ \\
\hline \multicolumn{4}{|l|}{ Sex } \\
\hline Male & $21(37.5 \%)$ & $199(59.76 \%)$ & 0.002 \\
\hline Female & $35(62.5 \%)$ & $134(40.24 \%)$ & \\
\hline \multicolumn{4}{|l|}{ Ethnicity } \\
\hline Brahmin & $23(41.07 \%)$ & $128(38.43 \%)$ & \\
\hline Chhetri & $12(21.43 \%)$ & $61(18.32 \%)$ & 0.243 \\
\hline Newar & $5(8.93 \%)$ & $67(20.12 \%)$ & \\
\hline Others & $16(28.57 \%)$ & $77(23.12 \%)$ & \\
\hline Smokers & $11(19.64 \%)$ & $71(21.32 \%)$ & 0.778 \\
\hline Alcohol consumers & $21(37.5 \%)$ & $153(45.95 \%)$ & 0.240 \\
\hline High total cholesterol & $27(48.2 \%)$ & $121(36.34 \%)$ & 0.090 \\
\hline High waist Circumference & $48(85.71 \%)$ & $62(18.62 \%)$ & $<0.001$ \\
\hline High waist: hip ratio & $51(91.07 \%)$ & $221(6.37 \%)$ & $<0.001$ \\
\hline BMI $\left(\mathrm{kg} / \mathrm{m}^{2}\right)$ Mean \pm SD & $28.93 \pm 4.20$ & $24.4 \pm 3.86$ & $<0.001$ \\
\hline
\end{tabular}

$\mathrm{p}$ value for age and BMI calculated by $t$ test. For other variables, $p$ value calculated by chi-square test.

Table 2: Prevalence of Metabolic Syndrome according to age group

\begin{tabular}{|lc|}
\hline Age group (years) & Metabolic Syndrome present in \\
\hline $20-39(n=165)$ & $5(3.03 \%)$ \\
$40-59(n=157)$ & $36(22.93 \%)$ \\
60 and above $(n=67)$ & $15(22.39 \%)$ \\
\hline
\end{tabular}

Table 3: Abnormalities of individual component of Metabolic Syndrome

\section{Components}

$\begin{array}{lc}\text { Waist circumference } & \begin{array}{c}\text { patients with the } \\ \text { abnormality }(\mathrm{n}=389)\end{array} \\ \text { (>102 cm for males, }>88 \mathrm{~cm} \text { for } & 110(28.28 \%) \\ \text { females) } & \\ \text { Blood Pressure ( } \geq 130 / 85 \mathrm{mmHg}) & 58(14.91 \%) \\ \text { Impaired fasting glucose } & 311(79.95 \%) \\ \text { (>100 mg/dL) or under medication } \\ \text { for diabetes } \\ \begin{array}{l}\text { Low HDL* }- \text { Cholesterol } \\ \text { (<40 mg/dL for males and }\end{array} \\ <50 \mathrm{mg} / \mathrm{dl} \text { for females) } \\ \begin{array}{l}\text { High Triglyceride ( } \geq 150 \mathrm{mg} / \mathrm{dL}) \\ \hline\end{array}\end{array}$

*High density lipoprotein
Table 4: Abnormalities of individual components in those with metabolic syndrome.

\begin{tabular}{lc}
\hline Components & $\begin{array}{c}\text { Number (\%) of metabolic } \\
\text { syndrome patients with the } \\
\text { abnormality }\end{array}$ \\
\hline Waist circumference & $19(33.93 \%)$ \\
\hline HDL $^{*}$ cholesterol & $34(60.71 \%)$ \\
\hline Triglyceride & $43(76.79 \%)$ \\
\hline Fasting Blood Sugar & $19(33.93 \%)$ \\
\hline Blood Pressure & $28(50.00 \%)$ \\
\hline
\end{tabular}

\section{DISCUSSION}

In this study, prevalence of metabolic syndrome was found to be $14.40 \%$ with higher prevalence in females $(20.71 \%)$ than in males $(9.55 \%)$. This figure is slightly less than that found in a population based study in eastern Nepal by Sharma SK et $\mathrm{al}^{10}$, which showed a prevalence of $20.7 \%$ according to NCEP criteria. According to the same criteria, $34.5 \%$ of the US adult population has been found to have metabolic syndrome ${ }^{12}$. The ICHR (Indian Council of Health Research) task force collaborative study has revealed the prevalence of metabolic syndrome in urban areas of Delhi to be $30 \%$ and $11 \%$ in rural Haryana using NCEP ATP III criteria. 
Mishra et al have reported 30\% prevalence among the urban population in Delhi ${ }^{13}$. Using modified NCEP ATP III criteria, Ramchandra et al ${ }^{14}$ from Chennai have reported prevalence of $41 \%$ in urban areas among adults 20 to 75 years of age. Metabolic syndrome was more common in females ( $46.4 \%$ vs. $36.4 \%$ ).

Among the baseline variables studied, occurrence of metabolic syndrome was associated with age (more common above 40 years), gender (more common in females), and obesity. Various studies have implicated obesity and sedentary lifestyle as risk factors for development of metabolic syndrome. In one study, individuals who watched television or played video games or worked in computer for more than four hours had two fold increase in risk of having metabolic syndrome than other individuals ${ }^{15}$. In the same study the approximate prevalence of metabolic syndrome in patients with coronary heart disease was found to be $50 \%{ }^{15}$. The prevalence of metabolic syndrome is high among obese children and adolescents, and it increases with worsening obesity ${ }^{10}$.

We studied abnormalities in each component of metabolic syndrome and distribution of these components in those with metabolic syndrome. Single most common abnormality among the participants was impaired fasting glucose or under medication for diabetes $(79.95 \%)$. But this component was present only in $33.93 \%$ of those with metabolic syndrome. High triglyceride on the other hand was present in more than three fourths of the metabolic syndrome patients. Next common abnormality was low HDL cholesterol. Thus, impaired lipid profile seems to be a common problem in those with metabolic syndrome. But individual components cannot singly predict metabolic syndrome. Hence one should actively look for all components as suggested in the guidelines.

All the components of metabolic syndrome can be controlled by dietary measures, regular exercise and medical treatment. Public should be made aware of this condition and they should be advised preventive measures.

\section{CONCLUSION}

The prevalence of metabolic syndrome in the present study has been found to be $14.40 \%$. It is more common in females and obese people. The most common component of metabolic syndrome was impaired fasting glucose $(79.92 \%)$. Presence of any one component should alert the physician to look for other components so that definitive diagnosis can be made and timely intervention can be commenced.

\section{ACKNOWLEDGEMENT}

The authors would like to thank Mrs. Ganga Pradhananga for recording the data and Mrs. Gayatri Mainali for typing the manuscript.

6. Ford ES, Li C, Sattav N. Metabolic Syndrome and incident diabetes: Current state of evidence. Diabetes Care. 2008;31(9):1898-904.

7. Ford ES. Risks of all-cause mortality, cardiovascular disease and diabetes associated with the Metabolic Syndrome: a summary of the evidence. Diabetes Care. 2005;28(7): 1769-78.

8. Galassi A, Reynolds K, He J. Metabolic Syndrome and risk of cardiovascular disease. Am J Med. 2006 Oct;119(10):812-9.

9. Gami AS, Wittt BJ, Howard DE, Erwin PJ, Gani LA, Somers VK, et al. Metabolic Syndrome and risk of incident cardiovascular events and risk and death: a systemic review and meta-analysis of longitudinal studies. J Am Coll Cardiol. 2007;49(4):403-14.

10. Sharma SK, Ghimire A, Radhakrishnan J, Thapa 
L, Shrestha NR, Paudel N, et al. Prevalence of hypertension, obesity and metabolic syndrome in Nepal. Int J Hypertens. 2011;2011:821971.

11. National Cholesterol Education Program (NCEP) Expert Panel on Detection, Evaluation, and Treatment of High Blood Cholesterol in Adults (Adult Treatment Panel III). Third Report of the National Cholesterol Education Program (NCEP) Expert Panel on Detection, Evaluation, and Treatment of High Blood Cholesterol in Adults (Adult Treatment Panel III) final report. Circulation. 2002 Dec 17;106(25):3143-421.

12. Ford ES. Prevalence of the metabolic syndrome defined by the International Diabetes Federation among adults in the US. Diabetes Care. 2005;28:2745-9.
13. Mishra A, Pandey RM, Devi JR, Sharma R, Vikram NK, Khanna N. High prevalence of diabetes, obesity, and dyslipidaemia in urban slum population in northern India. Int J Obes Relat Metab Disord. 2001;17:22-9.

14. Ramchandran A, Snehalatha C, Satyavani K, Sivasankari S, Vijay V. Metabolic Syndrome in urban Asian Indian adults - a population study using modified ATP-III criteria. Diabetes Res Clin Pract. 2003;60:199-204.

15. Powers AC. Diabetes Mellitus. In: Fauci SA, Braunwald E, Kasper LD, Hauser SL, Longo DL, Jameson JL, et al. Harrison's principles of internal medicine. 17th ed. Vol. 2. USA: McGraw Hill; 2008. p. 2275-304. 